\title{
The Use of L1 as a Teaching Strategyby Native and Non-Native EFL Instructors at a Language Preparatory Program in Turkey
}

\author{
Burcin Balabakgil \\ Bilgi University, Istanbul, Turkey \\ E-mail: burcinbalabakgil@gmail.com \\ Enisa Mede (Corresponding author) \\ Bahcesehir University, Istanbul, Turkey \\ E-mail: enisa.mede@es.bau.edu.tr
}

Doi:10.7575/aiac.alls.v.7n.6p.15

URL: http://dx.doi.org/10.7575/aiac.alls.v.7n.6p.15
Received: 14/07/2016

Accepted: 19/09/2016

\begin{abstract}
The purpose of this research study is to find out and compare the use of L1 as a teaching strategy by native and nonnative instructors in elementary level EFL classrooms at a preparatory program of a foundation (non-profit, private) university in Istanbul, Turkey. Specifically, the study aims to investigate the perceptions of native and non-native teachers of English about the use of L1 as a teaching strategy in their classrooms, explore how often and for what different teaching purposes they use learners' L1, and lastly, find out their reflections about L1 use in their classroom practices. The participants of this study were 30 EFL instructors ( $N=15$ native, $\mathrm{N}=15$ non-native) teaching elementary level learners at a foundation (non-profit, private) university in Istanbul, Turkey. The data were collected through a questionnaire $(\mathrm{N}=30)$, classroom observations $(\mathrm{N}=8)$ and think aloud protocols $(\mathrm{N}=8)$. The findings revealed that both native and non-native instructors had a highly positive attitude towards the use of L1 as a teaching strategy and they believed that it has a supportive role both for learning and teaching effectively in elementary level monolingual classes.
\end{abstract}

Keywords: L1 Use; Teaching Strategy; Native Instructors; Non-native Instructors, Monolingual Classroom; Think Aloud; English as a Foreign Language (EFL).

\section{Introduction}

Language learning and communication is a universal experience for people in all cultures. Children in all parts of the world develop their communication skills through acquiring language in the context of their own culture. Thus, they take the first steps to understanding the world around them and start interpreting it with their mother tongue. With rapidly globalizing world, however, people started to interpret the world around them not only through their mother tongue but also the universal language of the world; English.

Crystal (2000) estimates that there are 1.5 billion speakers of English around the globe, which means that one in four of the world's population communicates in this common language. In other words, one's proficiency in mother tongue is no longer adequate for him/her to communicate in the world $\mathrm{s} / \mathrm{he}$ is in unless s/he speaks English because it has become the global language of communication in all areas of social life; business, economy, diplomacy, media, academy etc. With this growing need and demand to learn the language of the world, English has also become a necessity for effective communication in higher education worldwide; and is the primary language of instruction, which makes it a requirement for many college and university students. However, for students who have not been exposed to English previously, this is a great challenge. They need to equip themselves with the necessary language skills and strategies in one year to be proficient enough to follow their undergraduate studies. Preparatory programs of universities, which promise to make students confident and fluent language users within a year so that they can successfully start their departmental studies, usually meet this need of learners. In order to offer the best opportunities for learners, preparatory programs try to hire qualified instructors in their fields, and implement the latest and most effective approaches in language teaching.

In Turkey, most English Language preparatory programs value the variety of instructors they employ and thus, they hire both native speaker instructors and non-native speaker instructors. Specifically, native instructors are mainly preferable due to their more comfortable and natural way of using the language. What's more, their repertoire of vocabulary and expressions are usually much richer compared to non-natives, which provides learners a more authentic learning experience. Non-native English instructors, on the other hand, can help and guide learners better in their language learning adventure as once they were conscious language learners and thus they are well aware of the possible problems the learners might experience when learning a new language. In addition to that, non-native English instructors have another important advantage over native English instructors; speaking learners' L1. Although some non-native instructors prefer not to use L1 at all, great many of them benefit from learners' mother tongue in teaching. 
Many native English instructors, who have spent considerable time in the country they work, improve their proficiency well enough to use the official language of that country. Interestingly, some of these instructors turn this into their advantage and benefit from it in their teaching practice. Specifically, they state that L1 is an essential part of the language learner identity and they consider the 'informed use' of it by the teacher as a great lifesaver. Some of them even indicate that they use learners' L1 as a fun element in the classroom because hearing a foreigner using their own mother tongue astonishes most of the learners.

Non-native instructors, on the other hand, generally make use of their own mother tongue more for making explanations and clarifications to highlight important language points. They argue that L1 helps them compare the systems of two languages and they usually benefit from metalanguage in L1 while doing so. This, alone, shows that native and nonnative teachers use learners' L1 as a teaching strategy for completely distinct purposes.

Based on these overviews, it is clear that the use of L1 as a teaching strategy in EFL classroom is still a controversial debate among EFL instructors and institutions. Mattioli (2004) believes that majority of language teachers tend to have assumptions about mother tongue use, depending on the way in which they were taught. According to Nazary (2008) many language teachers strongly believe that even a single word from the mother tongue should not be used in the EFL classroom and these teachers are the advocates of the 'Monolingual Approach'. Monolingual approach defends the idea that L2 should be the sole language of instruction to maximize exposure and learning of the target language and therefore the approach claims that the ideal teacher should be a native teacher (Miles, 2004). However, the monolingual approach has many criticisms. Miles (2004) supports the use of L1 and regards the monolingual approach as 'impractical' because he believes that exposure to target language is not sufficient for learning and NS teachers are not necessarily the best teachers for language instruction. According to Cook (2001), L1 always exists in learners' minds, and therefore, it would be artificial and even ineffective to avoid its use. Furthermore, as Macaro (2009) suggests restriction of mother tongue from the communicative EFL classroom could eventually provide fewer cognitive and metacognitive opportunities to learners.

In addition, there is a large population of instructors who stoutly defend the need of L1 under certain circumstances as it can enhance learning. The main argument for its defense is the facilitative role of L1 in teaching. As Harbord (1992) points out, majority of English language teachers worldwide are not native and the total banning of the learners' mother tongue in the classroom is usually a doubted issue. "This is also true of many native teachers who see the students' L1 as facilitative to the learning process" (Wharton, 2007, p. 4).

Following these discussions, Nation (2003) introduces an approach called 'Balanced Approach'. According to this approach, there is a need for L1 as it can function as a beneficial classroom tool to more effective performance in the TL. Besides, the approach defends that learners' L1 is more tolerable with lower levels considering their limited target language (TL) proficiency. Still, maximizing TL use in the classroom is a priority in balanced approach.

Furthermore, reasons for using mother tongue can be labeled using Ellis's (1988) distinction between two types of classroom interaction: 'medium-oriented goals,' where the focus is on the teaching of the target language itself, and 'framework goals,' which are related to the organization and execution of classroom events. As a medium-oriented goal, L1 is used to explain the meaning of new lexical items or to teach the grammar of the TL. As a framework goal, L1 can be used for purposes such as classroom management, assigning homework or planning exams.

Using first language/mother tongue in different grade classrooms is one of the most essential strategies to teach a second and/or foreign language. However, teachers differ in the ways they make use of this strategy; i.e. they use L1 in different incidences, situations or for different purposes. The purpose of this study, therefore, is to investigate the perceptions of native and non-native instructors about the use of L1 (Turkish) as a teaching strategy in L2 (English) classrooms, explore how often and for what purposes they use the first language in their classes and finally, reveal their reflections towards the use of L1 in their classrooms. In the light of the above discussion, this study aims to find the answers to these research questions:

1. What are the perceptions of the native and non-native instructors about the use of L1, Turkish as a teaching strategy in L2, elementary level English classrooms of a language preparatory program?

2. How often and for what purposes do native and non-native instructors use L1 in their classrooms?

3. Are there any differences between the use of L1 by native and non-native instructors? If yes, for what purposes do they adopt the use of L1 as a teaching strategy in their class practices?

4. What are the reflections of native and non-native instructors towards the use of L1 in their classroom practices?

\section{Literature Review}

\subsection{L1 Use in L2/EFL Classrooms}

For many instructors of English language, the notion of L1 use in language teaching and learning is regarded in the same equation with making use of the outdated grammar-translation methods, which made it a 'taboo' over the last century (Cook, 2001). According to Sharma (2006) L1 use has been a neglected topic in language teaching and it has been portrayed as a hindrance rather than help. Therefore, many biased L2 and/or EFL practitioners still totally ignore the L1 in their teaching practice, assuming that any link between the L1 and the TL would cause confusion for the learners. 
Another concern of language teachers is that their use of the L1 will inevitably result in student use of the L1 and thus they avoid it as much as possible. For this reason, L1 use was either banned or minimized in most EFL classrooms. The main misconception of language teachers regarding this issue is that more target language exposure leads to learning of it inevitably. Dujmovic, (2007) however, points out that excluding the learners' mother tongue for the sake of maximizing their exposure to target language is not necessarily beneficial because depriving students of L1 means not allowing any room for their self-expression. It is a natural phenomenon for a language learner to equate what he is learning with his L1; and thus ignoring this need would only lead to negative consequences which may even interfere with their learning.

Recently, increasing number of instructors and researchers are questioning whether limited mother tongue use interferes with foreign language learning. Butzkamm (2003) states that there has been a shift from a judicious use of the mother tongue to improve the learning and teaching of the target language to an interest in how mother tongue could be used to maximize learning in target language. Harbord (1992) argues that most language teachers have tried to create monolingual classrooms but have found they have failed to get the meaning across, which led to student confusion and indignation. He also supports the fact that translation is a natural phenomenon and an inevitable step of second language acquisition. Similarly, Macaro (2005) claims that most scholars now admit that even the most advanced language learners inevitably resort to their own mother tongue to process language and they believe that there is recognizable value in L1 to enhance learning at certain times. Most teachers now admit that they use L1 in English classrooms for a number of reasons such as clarifying meaning of difficult words, explaining complex grammar rules, discussing crosscultural issues or establishing close relationship with their students. Apart from that, most teachers agree that their students learn English more effectively; they feel easy and comfortable through the use of L1.

Furthermore, as Atkinson (1993) points out, most language learners of English are found in monolingual classes, and thus a great majority of English teachers in the world teach monolingual classes. First, the learners all share a common culture and a common language other than English and these classes are in countries where English is not the official or main language. The teachers also share the same language and culture as the learners. This may bring both problems and benefits to the classroom. Teachers of monolingual classes need to encourage learners to take every opportunity to study and practice English and they also need to put great effort to expose learners to English as much as possible. However, this does not mean that teachers should adopt an English-only approach. Instead, as Grant (1993) states, teachers should get the maximum benefit from L1 as a teaching tool because they are the ones who know how L1 can be incorporated as a teaching strategy in L2 classrooms effectively.

Another theory that advocates the use of L1 to teach TL is the 'Schema Theory' suggesting that cognitive knowledge is grouped into interrelated patterns (Nunan, 1999). Specifically, it is based on one's previous experiences regarding a given aspect of the observational world (i.e. their mother tongue) as well as allowing them to hypothesize about future experiences. Schema theorists suggest that we comprehend something only when we can relate it to something that we already know. Accordingly, "the process of interpretation is guided by the principle that every input is mapped against existing schema" (Carrell, 1983, p. 82). According to Lightbown and Spada (2013), many instructors and researchers do not doubt that learners use knowledge of the L1 to analyze the target language as it may help with the use of new material accessible to the learners' existing structure of knowledge, particularly at lower levels.

Furthermore, 'Cognitive Processing Theory' (Ellis, 2005) argues that the L1 and L2 are kept in connected conceptual stores and lexical items of the two languages are activated when a language learner attempts to process the TL. The reason behind this processing might be due to the fact that the language learner has already constructed a system of language to comprehend the target language based on his mother tongue principles. This concept is also explained as 'Interlanguage Theory', which tries to explain the internal system a language learner has developed and the series of interrelated systems characteristic of the learner's improvement over time. This theory also interprets how the brain functions and makes connections between L1 and L2 along with how L1 can influence linguistic and cognitive interpretations in L2.

\subsection{Functions of L1 in TL Learning}

Language instructors resort to learners' L1 for various reasons such as establishing social relationships, communicating complex meanings to ensure comprehension or saving time and classroom management (Littlewood \& Yu, 2011). Inbar-Lourie (2010) lists other functions of L1 in L2/EFL classroom as explaining and analyzing grammar, crosscultural discussions, explaining errors, providing feedback, checking comprehension and reducing anxiety of learners.

Wharton (2007) divides the ways learners' L1 is represented in the language classroom into three broad categories. The first category he defines is providing L1 equivalents of English words and expressions. As for the second category, he focuses on using L1 to focus on language in use; and finally the third category he focuses on is using L1 for classroom interaction.

The first category; providing L1 equivalents of words and expressions, is considered to be a very common strategy used by EFL teachers because of its time efficiency. According to Atkinson (1987), this strategy is usually preferred for techniques such as "eliciting language", "checking comprehension", "memorizing new vocabulary" or "discourse teaching". Instead of dealing with time-consuming 'inductive' teaching techniques, many teachers resort to translation, as it is more direct and timesaving although it is not necessarily better. Despite the fact that using L1 equivalents or meanings alongside L2 words is still a controversial issue among EFL instructors, Seibert (1945) found that providing paired lists with L1 equivalents was a superior approach for vocabulary memorization. A qualitative research by Liu 
(2008) also revealed that the proper application of L1 facilitated the memorization of new words by adult learners. He suggested that adult language learners already have a well-developed system of concepts and lexis. Therefore, when they acquire new target language vocabulary, they inevitably depend on corresponding concepts in their L1 by translating, which means that L1 plays an active role in their L2 learning process.

In another study about providing L1 equivalents, Masrai and Milton (2015) suggest that contrary to what is generally assumed, giving a word's translation is more effective for its retention than exposing learners to it frequently. In brief, the use of L1 in L2 classrooms is considered as an important strategy during the learners' language learning process and it can finally be concluded that there is no reason why L1 should not be considered as an effective tool for learners' understanding of TL word meaning.

Using L1 to focus on language is another common strategy Wharton (2007) remarks. Studies comparing the efficiency of various language learning methods generally come up with the result that providing L1 translation is considerably a more effective way of offering clearer, shorter and more direct explanations compared to other methods (Lado, Baldwin and Lobo 1967; Mishima 1967; Laufer and Shmueli 1997). This is a deductive approach to teaching grammar that many low-level learners want and many non-native speaker teachers provide in language classroom. This technique, which is peculiar to the grammar translation method, goes far beyond providing the equivalent of a word or the word-for-word translation of an expression. Instead, specific points about grammar usages are explained and exemplified in detail. Although EFL teachers underrate this technique because it ignores the context-meaning relationship, it can be a very useful way to raise learner consciousness.

According to Atkinson (1987, p. 244) using L1 for translation and "presentation and reinforcement of language" help early level learners focus on accuracy and notice the key structural differences between two languages. This can also help learners become more aware of how their mother tongue might hinder or facilitate their L2 learning. By considering these reasons, it might be deduced that using L1 translations and explanations would not only be helpful for low-level learners, but also for higher-level learners who have to deal with the meaning and use of complex structures thoroughly. By using L1 for this purpose, the teacher can clarify the complex grammar points and linguistic features more rapidly and allow more L2 practice to take place in the classroom.

The final category emphasized by Wharton (2007) is using L1 for classroom interaction. According to him, there are many ways the teachers or the students can make use of L1 as an interaction tool in the classroom. Atkinson (1987, p. 243) suggests that "at very low levels" communicative tasks can be very difficult for teachers to set up, and so using the students' L1 to give the instructions can save a lot of time, especially if the task is worth doing. He also recommends using students' L1 to discuss classroom methodology particularly at lower levels, because students have a right to know what they are doing in the classroom and why they are doing it. Therefore, the teacher can use L1 either to present a new type of task or explain why a particular task done in the classroom is useful for their language development. According to Atkinson (1987), classroom interaction does not always mean the interaction between the teachers and students; it can also be the interaction among students when they communicate with one another to compare their answers, to explain grammatical structures, to comment, to give feedback or to evaluate each other's performance in the classroom. Lameta-Tufuga (1994) investigated the effects of allowing students some time to discuss the task in their L1 before they carried it out in the target language. That is, they were given the opportunity to comprehend the content of the task through the use of their L1 before they started doing it. His findings showed that the learners were all actively engaged in the task and they came up with various ideas as they took advantage of their mother tongue for enhancing communication in TL. Besides, their pre-task L1 discussions included a lot of TL vocabulary that would be used later in the task. This supports the idea that L1 has a useful role in helping learners gain the knowledge they need to reach a higher level of TL performance.

As indicated in the aforementioned studies, L1 is considered to be an important strategy in L2/EFL classroom because of its supportive role during the language learning process.

\subsection{Factors Affecting L1 and TL Use in Teaching}

The most important factor that determines the amount of L1 use in class is learners' level of language proficiency. Cole (1998) points out that L1 is most useful at beginning and low levels in order to introduce to major differences between L1 and L2 or to raise awareness on main grammatical characteristics of L2. However, as Butzkamm (2003) states, mother tongue becomes unnecessary with growing proficiency in the foreign language. In other words, the higher gets the level of the learners, the less reason there is to use L1. At higher levels, the use of L1 can even be considered unnecessary except for exceptional circumstances.

Connick-Hirtz (2001) poses the following questions for teachers to consider before they decide to use L1 in their classrooms:

- What is the learners' first language?

- What is the learners' age?

- Are we teaching beginners or advanced levels?

- What is the ratio of students/teaching time per one class?

- How long is the learner going to study the second language?

- What are his/her learning purposes?

- Is it a one nationality or mixed nationality group?

- What is the institution's pedagogical policy? 
- What kind of educational background does the learner have?

- In what kind of social context is the teaching of L2 taking place?

Furthermore, an important factor that determines the L1 use in the classroom might be the students' previous language learning experience. If the students are used to being taught mainly in L1, the teachers may need to increase the amount of TL use in a gradual way so that the students do not feel alienated from the classroom with the exclusive use of the TL.

Another significant determiner that should be taken into consideration is the stage of the course or lesson. At the initial stages of learning, the teacher might use L1 to reduce the level of stress and anxiety, or to establish rapport with the students. As the teacher and the students get to know each other, it would be pointless to do activities in L1.

To wrap up, there are times when L1 can play a central role while there are stages when the L1 should never be used. Therefore, when the instructors make their decision, they should take all the factors into consideration.

\subsection{Advantages of Using $L 1$}

Although 'English only' attitude to teaching was frowned upon, there was no serious challenge to it until Swan (1985) started to strongly emphasize its advantages in 1980s. He argued that even though language learners may make errors due to interference from the L1, vast majority of what learners get right is done with reference to it as well. He also underlines that people do not have 'blank slates' and we should depend on our existing knowledge for comparison, rather than trying to understand the world and everything in it from scratch.

Another important reason why teachers make use of L1 is it is time-efficient on many occasions. Viney (2005) points out that in cases where majority of the learners can deduce a word and a couple cannot, it is more efficient for the instructors to give a quick translation rather than spending time on paraphrasing, miming etc.

In addition, Al-Hinai (2006, p. 1) highlights the other advantages of using L1 as follows:

1. It reduces learner anxiety and creates a more relaxing learning environment,

2. It is a means of bringing the learners' cultural background knowledge into the class,

3. It facilitates checking understanding and giving instructions,

4. It facilitates the task of explaining the meaning of abstract words and of introducing the main differences in grammar and pronunciation between L1 and L2.

In a similar fashion, Butzkamm (2003) mentions that L1 use gives learners a sense of security and helps them to be stress-free, which saves them from a feeling of frustration they might have within their language learning. Apart from this, he claims, "all newly acquired foreign language items have to sink roots in our minds, which are eventually deep enough for the items to function independently of the L1" (p. 36).

Willis (1991) also suggests that instructors can make economical use of mother tongue when explaining the meaning or use of new words, introducing the aims of the lesson or an activity or to check students' understanding after the presentation stage to make sure students know what they are learning.

Grant (1993) suggests that the use of mother tongue can bring a lot of cognitive benefits if used with translation activities. One of the benefits is that translation forces learners to think about the meaning and social appropriacy by allowing them to think comparatively. When they do so, they become more aware of the similarities and differences between two languages and reduce the risk of making typical interference mistakes.

Another benefit of translation for language learners is that it is a real life activity and it is very likely that some learners will spend time translating in their future jobs. Although some linguists such as Chaudron (1988), Krashen (1982) and Macdonald (1993) are strongly in favor of using target language in the classroom, Cook et al. (1979) points out that learning a target language is not simply a matter of syntax and vocabulary; rather it is environmental, linguistic as well as emotional.

Total banning of the L1 in monolingual classes prevent students from expressing themselves clearly and effectively, which leads to communication problems such as misunderstandings in the classroom. Harbord (1992, p. 351) sees "humanistic element" as a reasonable attitude towards the use of the students' mother tongue and considers it highly unlikely that a teacher would refuse to answer a question like "What does ... mean in English?".

Auerbach (1993) goes further on this issue even to claim that forcing people to use only L2 violates human rights as it means to impose ideological control on them. In other words, forcing people to use the TL may aim to break one's ties with his or her native language and culture or identity. Thus, many scholars and instructors agree that students should be allowed to express what they want to say in their L1 and then the teacher can help them articulate it in English.

Cook (2007) criticizes the fact that language teachers neglect translation and adopt a monolingual (target-language only) approach to teaching English. According to her, since culture is a part of the language, neglecting learners' L1 in the classroom also means neglecting learners' culture, which might lead to the danger of rejecting their identity. In addition to the cultural aspect, there is no valid data that confirms monolingual approach is the best. On the opposite, disregarding students' mother tongue can be de-motivating and make them less enthusiastic to learn the target language. 
Furthermore, in one of his studies, Levine (2003) examined university students' anxiety level in relation to the frequency of L1 use in class. Surprisingly, he found that the TL amount had negative correlation with students' perception of anxiety and students felt less anxious when exposed to certain amount of mother tongue. L1 also help learners and teachers establish better rapport and thus have better communication. Some students in the same study even reported that L1 provides positive relationships to be built not only between them and their teachers, but also among all members of the class. Overall, the statements of many studies show that students view L1 as a significant factor to reduce anxiety and foster positive classroom atmosphere.

A study conducted by Rolin-Ianziti and Varshney (2008), which attempted to investigate teachers 'reasons for codeswitching and learners' views on the use of L1, revealed that the learners attribute a role to the L1 in their understanding of vocabulary and grammar. In terms of vocabulary, the use of the first language helps them access the meaning of words and it also facilitates memorization.

In addition to vocabulary, learners also indicate that L1 facilitates understanding of grammar, especially when complex grammar items are explained in detail. Therefore, it can be deduced that the learners see L1 as an element that reduces the risk of misunderstanding and confusion. In other words, L1 serves as a tool of confirmation; assuring learners that they understood every language point correctly and didn't miss anything.

\subsection{Disadvantages of Using L1}

In monolingual setting, language learners have very little opportunity to practice the TL outside the classroom. Therefore, every second TL is not spoken in the classroom is considered a 'time wasted' for many instructors. This is also true for many language learners who want to spend their limited time in an English-only atmosphere. Researchers like Ellis (1984) claim that more L2 acquisition can only take place in the absence of L1 since frequent use of it creates over-dependency and thus can be an obstacle to learn the target language. Atkinson (1987) suggests that learners need to be encouraged to improve communication strategies and made aware how much they are able to do with their limited language. In order to achieve this, learners should not depend on their L1 no matter how low their levels are because depending on L1 might easily become a habit and reduce the time TL is spoken in the classroom.

Kavaliauskiene (2009) emphasizes the negative effects of translation caused by cross-linguistic similarities and differences between the two languages. These negative effects are underproduction, overproduction, production errors and misinterpretation. Another drawback Kavaliauskiene (2009) highlights about the use of L1 is, it can cause students to think that words or structures in English have an L1 equivalent, which does not always exist.

For reasons above, some researchers and instructors suggest that language teaching should take place exclusively in the target language. Thus they are totally against L1 translations of the target language with the purpose of teaching. Instead of resorting to L1, they point out that the instructors should make use of other techniques and maximize the use of TL in class.

\subsection{Relevant Studies on L1 Use in ESL/EFL Classrooms}

Most ESL/EFL teachers worldwide are non-native and a large number of them regard using L1 to teach a foreign language as a necessity on many occasions. Many studies emphasized the positive attitudes of both instructors and learners towards L1 use because of its supportive functions (Tang, 2002; Cook, 2002; Schweer, 1999; Burden, 2000; Sharma, 2006; Prodromou, 2002; Kayaoğlu, 2012; Nazary, 2008; Macaro, 1997; Rolin-Ianziti \& Varsney, 2008).

To begin with, Tang (2002) studied the use of the L1 by Chinese instructors of English and learners' attitudes towards it. The results showed that both instructors and learners reacted positively to using L1 as a facilitative means of teaching.

Cook (2002) points out that learners are also more likely to identify with and to be able to emulate non-native instructors (NNS) than native instructors (NS). One reason for that is, NNS instructors are usually more sensitive to the difficulties faced by the learners.

Schweer (1999) surveyed his students at a Puerto Rican university and found that $88.7 \%$ of his students and $100 \%$ of the instructors felt that the L1 should be used in the English classroom. He also compared his results to another study conducted by Tang (2002) and found that both studies showed that the mother tongue was used by most instructors; and both students and instructors had positive reactions toward its use. The research showed that limited and responsible use of the mother tongue in the language classroom does not reduce learners' exposure to the TL but rather assist in teaching and learning process.

In a survey of 290 university students, Burden (2000) found that 73\% thought both NS instructors and students should speak some mother tongue in the classroom. Likewise, another study conducted in Kansai University showed that $85 \%$ of students responded that the teacher should make use of the mother tongue in the classroom while $60 \%$ thought they should be able to make use of it as well.

A research conducted by Sharma (2006) revealed that more experienced teachers highly feel the need of using L1 in comparison to less experienced teachers. A possible reason for that could be that new teachers are more willing to put the new methodology they have learnt into practice while experienced teachers have seen L1's practical benefit in teaching and thus habituated to use it. 
In his more in-depth research, Prodromou (2002) divided learners into three groups of proficiency; elementary, intermediate and advanced to investigate the reaction and attitude of these learners towards L1 use in class. His findings showed that learners at higher levels have a negative attitude toward the use of L1 while learners at lower levels accepted the use of their mother tongue more positively.

Besides, a study by Kayaoğlu (2012), which aimed to explore teachers and students' preferences regarding L1 use in Turkey found that vast majority of teachers (97.7\%) agreed upon and strongly recommended the idea that beginner level students learn English grammar easier when it is explained in Turkish. The participants of this study also agreed on the necessity of the teachers' L1 use in foreign language classrooms in general and thought it was a motivating factor in their language learning.

The findings of a study conducted by Nazary (2008) at an Iranian university show that the university students were reluctant to use their mother tongue in English classroom and they strongly rejected it for greater exposure to L2 no matter what their proficiency levels are. Surprisingly, however, $81 \%$ of students at advanced levels and about $68 \%$ of students at elementary and intermediate level believed that the teacher should know the students' L1.

Data collected by Macaro (1997) on learners' attitudes towards teachers' L1 and TL use in class revealed that while minority of the learners did not react to great amount of TL exposure, the majority got frustrated being exposed to TL use without any assistance in L1. Yet, these two groups reached a consensus on the necessity of L1 to understand teachers' instructions for classroom activities or homework.

Learner participants in Rolin-Ianziti and Varsney's study (2008) perceive L1 as detrimental to the goals of an ideal language classroom as the frequent use of it does not force them to understand the TL. They stated that L1 use reduces their concentration and makes learning less challenging since they rely on mother tongue explanations. They also pointed out that the lack of effort and challenge produces a loss of self-confidence and motivation to understand or learn the TL.

Based on these overviews it is possible to say that for many language learners, L1 seems to have an important role in gaining explicit knowledge of linguistic features of the TL. However, they are also aware of the fact that exposure to the TL is essential and the more they are exposed to the language the more competent they will get.

Apart from the research on the use of L1 in L2/EFL classrooms abroad, many studies have been conducted with an attempt to understand teachers' and students' perceptions about L1 (Turkish) use as a language of instruction in EFL classrooms in Turkey as well (Devrim \& Bayyurt, 2010; Kayaoğlu, 2012; Yavuz, 2012; Mahmutoğlu and K1cır, 2013).

To begin with, a study by Devrim and Bayyurt (2010) analyzed what students thought about the nationality of their English teachers. Majority of students in this study agreed that they would prefer native English language teachers, yet they also ranked native teachers who could speak Turkish in the first place.

A study by Yavuz (2012) showed that the teachers make use of Turkish the least while teaching communicative skills such as listening or speaking and rely more on it while teaching structural points such as grammar. The teachers also indicated that the main reasons that lead them to Turkish use are crowded classrooms and lack of interest.

In a similar study by Kayaoğlu (2012), the findings from the interviews showed that teachers see the use of Turkish as a motivating factor in students' language learning. However, most teachers agreed that the use of Turkish should vary according to skill and students' levels. They also asserted that they use L1 in their grammar courses especially at beginner levels and they highly recommend it to their colleagues. Some teachers in this study stated that L1 strengthened students' skills and helped teachers to simplify difficult topics, support classroom management and build good rapport with the students. Additionally, the teachers expressed that Turkish facilitated learning and made it more efficient by saving them time. As a result, the instructors are competent with the use of L1 in the classroom both for motivational and instructional purposes as it has positive implications in the classroom.

Another study by Mahmutoğlu and Kıcır (2013) revealed that students believe mother tongue should be 'usually' used in English classrooms while the teachers believe it should 'sometimes' be adopted. The teachers' and students' beliefs showed parallelism in that Turkish should be used to explain grammar concepts and to explain the differences between Turkish and English in terms of grammar. The second area that both groups agreed upon was that Turkish should be used to explain the meaning of abstract words. Overall, the results of the study revealed that teachers had a positive attitude toward the integration of Turkish into English classroom particularly to create a supportive classroom, give instructions and teach grammar at early stages of learning. Likewise, the students' perceptions on L1 were similar, as they believed in the benefit of teachers' use of L1 to explain grammar and to present the meaning of abstract vocabulary concepts.

\section{Methodology}

The following section explains the methodological procedures applied in the study.

\subsection{Design of the Study}

For the purposes of this study, mixed method research design was adopted in interpreting both the quantitative and qualitative data.

\subsection{Setting and Participants}

This study was conducted at an English Language Program offered at a foundation (non-profit, private) university in Istanbul, Turkey. In this program, all students take a proficiency exam at the beginning of the academic year. The ones 
who score 60 and above (out of 100) can directly start their departmental studies whereas ones who score below 60 must take a placement test. According to their gained scores from the placement exam, they are placed in different proficiency level classes at the preparatory program.

The aim of the preparatory program is to prepare learners for their departments at various disciplines by providing them with an intensive English course within an academic year. The program has five proficiency levels (A1, A2, B1, B2, C1) designed in compliance with Common European Framework (CEFR/CEF). At each level, the learners receive 8 weeks of instruction, which is referred as one teaching module. Each level -except for Level 1 (beginner) - comprises three courses; Main Course, Reading-Writing and Speaking. Main Course focuses more on grammar and vocabulary, which are also integrated to listening materials. In Reading-Writing lessons, learners focus more on comprehending academic texts and writing academic essays. Speaking lessons provide learners with communicative practice to improve sub-skills such as turn taking, keeping the conversation going etc. At the end of each module, the students are required take the Achievement Test (AT). In order to progress to subsequent levels, the average of a learner's AT and the other tasks and quizzes needs to be minimum 60 (out of 100). The students have the right to exit the preparatory program provided that they complete all the levels they are required to.

The participants in this study were 30 EFL instructors (20 females and 10 males) working at the English Language Preparatory program. Their age range was 25-65 with 3-30 years of teaching experience. All instructors had teaching experience at a private university and taught main course components at different levels. All of the instructors were teaching elementary (CEFR A2) level classes.

The non-native instructors $(\mathrm{N}=15)$ were all Turkish and they were females. They had strong English language background as they were graduates of English Language Teaching $(\mathrm{N}=8)$, English Language and Literature $(\mathrm{N}=4)$, American Culture and Literature $(\mathrm{N}=2)$ and Linguistics $(\mathrm{N}=1)$ departments. All instructors, except English Language Teaching graduates, had a pedagogical formation certificate which shows their eligibility to teach English in second and/or foreign language classrooms. In addition, 4 instructors had an MA degree in English Language Teaching while three of them are currently studying in an MA program. Finally, 7 instructors had a Cambridge CELTA (Certificate in Teaching English to Speakers of Other Languages).

As for the native instructors of English $(\mathrm{N}=15)$, they came either from the USA $(\mathrm{N}=8)$, the UK $(\mathrm{N}=5)$ or $\mathrm{Canada}(\mathrm{N}=2)$ where English is a spoken as a native language. None of the native instructors were graduates of the department of English Language Teaching (ELT). However, they all hold an internationally recognized teaching certificate such as, CELTA (N=6), DELTA (Diploma in Teaching English to Speakers of Other Languages, N=2), TEFL (Teaching English as a Foreign Language, $\mathrm{N}=4$ ) and TESOL (Teaching English as a Second Language, N=4). Finally, 2 of these instructors have completed their MA in ELT-related fields; MA in Education and TESOL.

\subsection{Instruments}

In this research, data were collected through a questionnaire, classroom observations and think aloud protocols. The following section describes each instrument in detail.

To begin with, the questionnaire in this study, adopted from Al-Buraiki (2008) and Sharma (2006) aimed to discover the perceptions of NS and NNS instructors about the use of L1 in L2 classrooms. The questionnaire was administered to all EFL instructors (NNS=15, NS=15) teaching elementary (CEFR A2) classes in the English Language Program to find out their perceptions towards the use of L1 (Turkish) in L2 (English) classrooms. In the questionnaire, there were a total of 10 questions for NS instructors and 8 questions for NNS instructors in two different types; questions at agreement scales, and multiple-choice questions. The participants specified their level of agreement at a 5 point Likert type scale ranging from 'strongly agree' to 'strongly disagree'. All questions attempted to find out the perceptions of NS and NNS instructors about the use of L1 in the preparatory program.

After the analysis of the questionnaire responses, 4 NS and 4 NNS instructors who received the highest scores towards the use of the L1 as a teaching strategy in EFL classrooms were chosen for classroom observations and think aloud protocols.

In order to find out how frequently and for what purposes the two groups of instructors used L1, 4 NS and 4 NNS were observed during their classroom practices. Also, to ease the comparison of the items for the two participating groups, the researcher used two classroom observation track sheets (one for NS instructors and one for NNS instructors) during the observations. The observation track sheet adopted from Sharma (2006) included ten functions of an instructor's L1 use in L2 classrooms namely; explaining grammar, translating vocabulary or sentences, giving instructions, checking understanding, eliciting language, focusing learners' attention, talking about learning, giving feedback, disciplining/class control and informal/friendly talk with learners.

As the last data collection instrument, think-aloud protocols were used to discover the purposes of NNS and NS instructors about the use of L1 (Turkish) as well as to find out the reflections behind their preferences of L1 use in EFL classrooms. Think Aloud Protocol aims to gather qualitative information basing on the interpretation and justification of the participant's actions. Participants are asked to voice the words in their minds as they answer the researcher's questions. According to Charters (2003), there are generally two methods of conducting think aloud protocols: concurrent think aloud protocol which aims to collect data during the task, and retrospective think aloud protocol that attempts to obtain data after the task and the participant goes over the steps they took previously. Therefore, a visual reminder such as video replay usually stimulates the think aloud protocol. Based on this perspective, 8 English lessons 
(4 NS and $4 \mathrm{NNS}$ ) were video recorded by the researcher to seek correlation between what they say and what they actually do in practice regarding the use of L1 as a teaching strategy in EFL classrooms.

After the video recording of the observed classes (4 NS and 4 NNS), the researcher watched the videos with each participant individually. The researcher stopped the video at certain times and asked the two groups of participants to reflect on their teaching practices. The questions were adapted from Al-Buraiki's (2008) study which aimed to explore the perceptions of EFL instructors. Particularly, the questions focused on the purposes of L1 use and the factors affecting this use during the lessons observed. Specifically, the questions aimed to find out whether the use of L1 was a helpful strategy in EFL classrooms.

\subsection{Data Analysis}

In an attempt to answer the first question of the research, the data were gathered through a questionnaire administered to $15 \mathrm{NS}$ and $15 \mathrm{NNS}$ instructors. Google Forms automatically analyzed the results gained from the questionnaire in numbers.

For the second and third research questions, the data were gathered through classroom observations through a checklist used by the researcher. The results of the checklist were entered separately for 4 NS and 4 NNS instructors. To determine the frequency of L1 use, each word uttered by the instructors in Turkish were counted and entered into the observation track sheet and the total numbers were calculated for a deeper analysis. Then the results were compared for both groups.

Finally, for the last question, a total of 8 English classes that were previously observed by the researcher ( 4 NS and 4 NNS) were video recorded and transcribed to be recalled later. A few days after the observation, the researcher and the participants watched the videos and read the transcriptions to reflect on the lesson in the think aloud protocols. The obtained data were interpreted qualitatively through content analysis (Miles \& Huberman, 1994). The process began with the open coding of the data followed by inducing categories from these codes, which were then gathered under the aspects of the use of L1 as a teaching strategy in EFL classrooms. The categories and themes were subject to the checking of inter-raters.

To identify the degree of inter-rater reliability, two experts in the field of English Language Teaching (ELT) identified themes from the codes. It emerged that the raters achieved $87 \%$ of agreement on the general themes apart from the different verbalizations of similar concepts.

\section{Findings}

In this section, the findings were grouped into three sections; the perceptions of NS and NNS about L1 use as a teaching strategy, the frequency and purpose of L1 use by two groups of instructors and lastly, their reflections regarding the use of L1 in EFL classrooms.

\subsection{The Perceptions of NS and NNS Instructors about Using L1 as a Teaching Strategy in EFL Classrooms}

In an attempt to find an answer to the first research question about the perceptions of instructors about using L1 as teaching strategy, the data were obtained through questionnaires and classroom observations. As the sample size was not very high ( $\mathrm{NS}=15$ and $\mathrm{NNS}=15$ ), the numbers were reported for each respondent's answer to the questionnaire.

To begin with, the perceptions of the NNS instructors for each item are depicted in the table below.

Table 1. Perceptions of NNS about using L1 as a teaching strategy in EFL classrooms

\begin{tabular}{|c|c|c|c|c|c|c|}
\hline $\begin{array}{c}\text { Item } \\
\text { No }\end{array}$ & L1 should be used in an EFL classroom to... & SA & A & $\mathrm{S}$ & $\mathrm{D}$ & SD \\
\hline 1 & teach the target language more effectively & - & 8 & 7 & - & - \\
\hline 2 & help learners learn the target language more effectively & 3 & 10 & 2 & - & - \\
\hline 3 & help define/explain new vocabulary items & 4 & 4 & 6 & - & 1 \\
\hline 4 & explain complex grammar points & 4 & 7 & 2 & - & 2 \\
\hline 5 & explain difficult concepts or ideas & 3 & 11 & 1 & - & - \\
\hline 6 & practice the use of some phrases and expressions & 1 & 4 & 3 & - & 7 \\
\hline 7 & check understanding (of talk, text or instructions) & 1 & 4 & 7 & - & 3 \\
\hline 8 & elicit language & 2 & 4 & 6 & - & 3 \\
\hline 9 & give instructions & 1 & 2 & 6 & - & 6 \\
\hline 10 & motivate students (e.g. telling jokes, riddles etc.) & 8 & 5 & 2 & - & - \\
\hline 11 & give feedback & 6 & 8 & 1 & - & - \\
\hline 12 & give suggestions on how to learn effectively & 6 & 7 & 2 & - & - \\
\hline 13 & help learners understand new concepts & - & 9 & 2 & 3 & 1 \\
\hline 14 & help learners understand new vocabulary & 1 & 6 & 2 & 5 & 1 \\
\hline
\end{tabular}




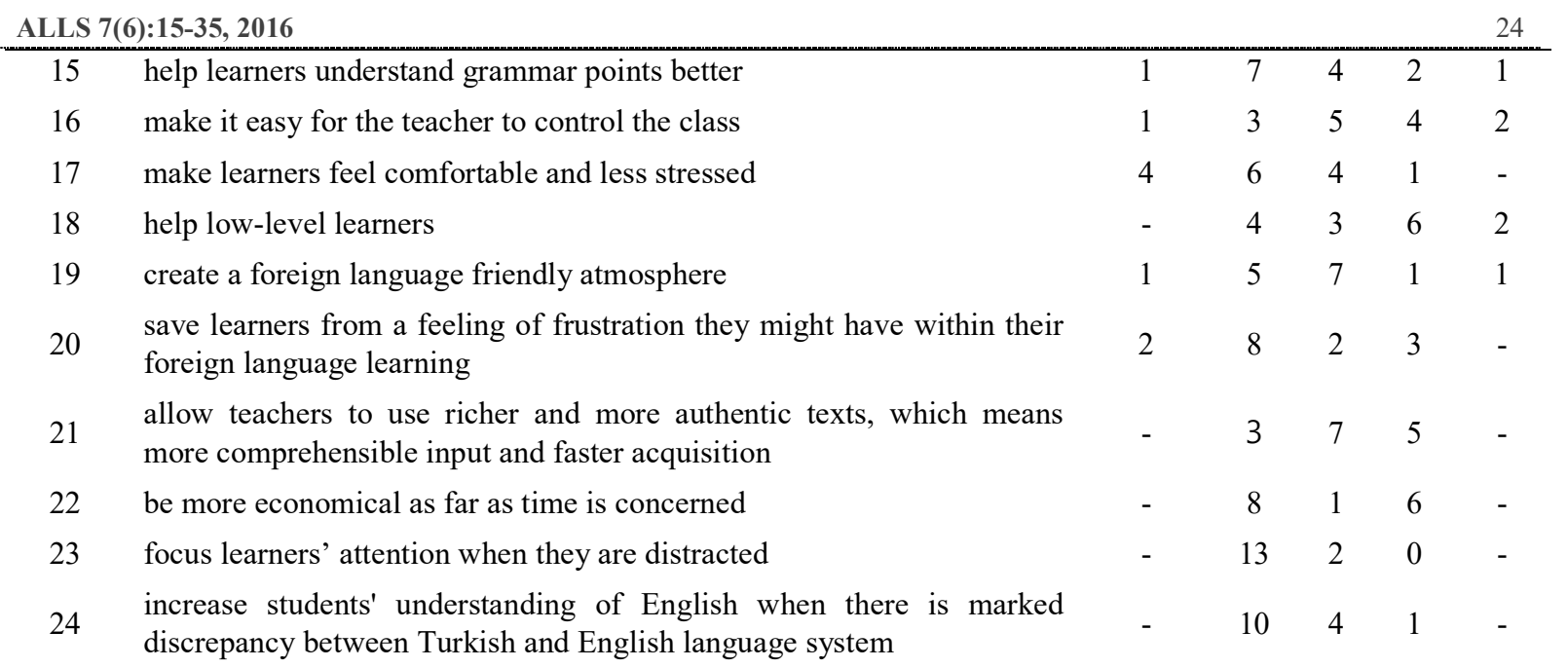

Note: SA: Strongly agree, A: Agree, S: Somewhat agree, D: Disagree, SD: Strongly disagree

As shown in the table above, the NNS instructors perceived the use of L1 as a teaching strategy in elementary level EFL classrooms highly positively. Specifically, 8 of the instructors agreed while 7 others somewhat agreed with the use of Turkish to teach English more effectively (item 1). Moreover, majority of the instructors (3 instructors strongly agree, 10 instructors agree) believed that the use of Turkish in the classroom help learners learn the TL (item 2) more effectively, especially for the comprehension of complex grammar points and explanation of difficult concepts or ideas. Another item (item 5) that most NNS instructors agree upon (3 instructors strongly agree, 11 instructors agree) is the function of L1 in the classroom to explain difficult concepts or ideas.

Furthermore, in an attempt to answer the question of what percentage of time L1 should be used in EFL classrooms, 7 instructors responded $10 \%$ or below, 4 instructors responded $20 \%$ and 4 instructors responded $30 \%$. As for the course/skills where L1 can be more necessary, 6 instructors responded 'writing', 4 instructors responded 'grammar', 2 instructors responded 'reading', and 1 instructor responded 'vocabulary', 'discourse' and 'speaking' each. None of the instructors thought L1 use was necessary to teach 'listening' or 'pronunciation'.

The same questionnaire was also directed at the NS instructors in order to find out their perceptions about L1 use as a teaching strategy in the class. The results of their perceptions are expressed in numbers in the table below.

Table 2. Perceptions of NS about Using L1 as a Teaching Strategy in EFL Classrooms

\begin{tabular}{|c|c|c|c|c|c|c|}
\hline Item No & L1 should be used in an EFL classroom to... & SA & $\mathrm{A}$ & $\mathrm{S}$ & $\mathrm{D}$ & $\mathrm{SD}$ \\
\hline 1 & teach the target language more effectively & - & 10 & 4 & - & 1 \\
\hline 2 & help learners learn the target language more effectively & 1 & 12 & 1 & - & 1 \\
\hline 3 & help define/explain new vocabulary items & 2 & 8 & 4 & - & 1 \\
\hline 4 & explain complex grammar points & 3 & 6 & 2 & - & 4 \\
\hline 5 & explain difficult concepts or ideas & 3 & 7 & 1 & - & 4 \\
\hline 6 & practice the use of some phrases and expressions & 1 & 3 & 5 & - & 6 \\
\hline 7 & check understanding (of talk, text or instructions) & - & 5 & 5 & - & 5 \\
\hline 8 & elicit language & - & 3 & 6 & - & 6 \\
\hline 9 & give instructions & - & 5 & 3 & - & 7 \\
\hline 10 & motivate students (e.g. telling jokes, riddles etc.) & 2 & 7 & 5 & - & 1 \\
\hline 11 & give feedback & - & 5 & 5 & - & 5 \\
\hline 12 & give suggestions on how to learn effectively & 2 & 5 & 4 & - & 4 \\
\hline 13 & help learners understand new concepts & 1 & 5 & 3 & 5 & 1 \\
\hline 14 & help learners understand new vocabulary & 1 & 7 & 4 & 2 & 1 \\
\hline 15 & help learners understand grammar points better & 3 & 8 & 1 & 1 & 2 \\
\hline 16 & make it easy for the teacher to control the class & - & 5 & 3 & 5 & 2 \\
\hline 17 & make learners feel comfortable and less stressed & - & 8 & 5 & 1 & 1 \\
\hline 18 & help low-level learners & 1 & 3 & 3 & 6 & 2 \\
\hline 19 & create a foreign language friendly atmosphere & - & 9 & 3 & - & 3 \\
\hline
\end{tabular}




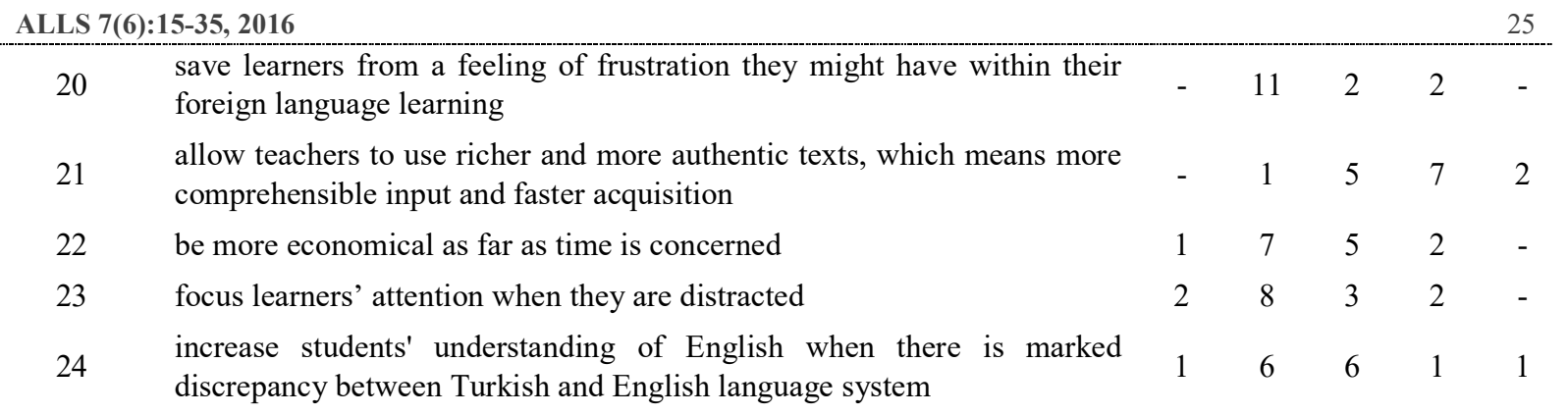

Note: SA: Strongly agree, A: Agree, S: Somewhat agree, D: Disagree, SD: Strongly disagree

When the answers of the NS participants to items 1, 2 and 5 about the efficiency of L1 were analyzed, it was observed that they also shared positive perceptions towards the use of L1 in English elementary level classrooms. Similar to NNS, majority of NS instructors (10 instructors agree, 4 instructors somewhat agree) that Turkish should be used to teach English more effectively (item 1) and help learners learn it more effectively (1 instructor strongly agree, 12 strongly agree - item 2). What's more, most NS instructors (3 instructors strongly agree, 10 instructors agree) believe that L1 (Turkish) should be used to explain difficult concepts and ideas (item 5).

To the question of what percentage of time L1 should be used in the class, 11 instructors responded $10 \%$ or below, 3 instructors responded $20 \%$ and 1 instructor responded 30\%. As for the course/skills where L1) can be more necessary, 6 instructors responded 'vocabulary', 5 instructors responded 'writing', and 4 instructors responded 'grammar'. None of the instructors thought L1 use was necessary to teach any other skills.

Finally, an additional question addressed only to NS was whether they thought an NS instructor should acquire some knowledge of learners' L1. As a result, 11 instructors (7 agree, 4 strongly agree) thought that acquiring some knowledge of L1 is a necessity while teaching the target language in their classrooms.

Apart from the questionnaire findings, the think-aloud protocols carried out with the two groups revealed similar findings. To put it simply, both NS and NNS agreed that use of L1 enables comprehension in EFL classrooms. They stated that using Turkish is helpful while explaining complex grammar rules and teaching abstract vocabulary items. The following comments were made by two native and two non-native instructors:

[...] I can definitely say that the use of Turkish makes comprehension easier in the class (NNS instructor, Think aloud protocol data, $23^{\text {rd }}$ March, 2016).

[...] Absolutely, L1 helps them understand better especially if I am teaching abstract words or difficult grammar points (NNS instructor, Think aloud protocol data, 23 ${ }^{\text {rd }}$ March, 2016).

[...] Yeah, sure it does help particularly if there is a complicated grammar point. I just give an example from Turkish and of course it really helps (NS instructor, Think aloud protocol data, $23^{\text {rd }}$ March, 2016).

[...] I think Turkish helps with student understanding especially if the word is abstract and the grammar rule is difficult (NS instructor, Think aloud protocol data, $23^{\text {rd }}$ March, 2016).

Moreover, both groups of instructors strongly agreed that L1 should be used to explain grammar on condition that learners are low-level. The following statements were made by two native and two non-native instructors:

[...] At lower levels, I definitely agree with the fact that they need more Turkish because they know nothing or very little about English and they have no background to build on (NS instructor, Think aloud protocol data, $23^{\text {rd }}$ March, 2016).

[...] The most important thing was the low level of the learners because at higher levels I never use Turkish to help students (NS instructor, Think aloud protocol data, 23 ${ }^{\text {rd }}$ March, 2016).

[...] I can definitely say that the use of Turkish eases comprehension, especially at lower level classes. If I had been teaching a higher-level class, I would not have used Turkish that much (NNS instructor, Think aloud protocol data, 23 ${ }^{\text {rd }}$ March, 2016). 
[...] At lower levels L1 fills the gaps where something is not clearly understood, especially if this is something abstract (NNS instructor, Think aloud protocol data, $23^{\text {rd }}$ March, 2016).

Based on these overviews, it can be concluded from the findings that, both NS and NNS instructors see L1 as a practical tool, which they can benefit from for various purposes in their teaching practices.

\subsection{The Purpose and Frequency of L1 Use by the NS and NNS Instructors in EFL Classrooms}

As for the answer to the second and third research questions about the purpose and frequency of using L1 in EFL classrooms, and the differences between the use of L1 by NS and NNS instructors, the data were obtained through classroom observations. Using a checklist, the number of times that the instructors used Turkish in class was recorded for each teaching purpose. The following table provides the purposes and frequencies of using L1 by each group of instructors.

Table 3. The purpose and frequency of L1 use by NS and NNS in EFL classrooms

\begin{tabular}{|c|c|c|c|c|c|c|c|c|c|c|}
\hline $\begin{array}{c}\text { Occasio } \\
n\end{array}$ & $\begin{array}{l}\text { Explainin } \\
\mathrm{g} \\
\text { Grammar }\end{array}$ & $\begin{array}{c}\text { Translatin } \\
\mathrm{g} \\
\text { Vocabular } \\
\text { y or } \\
\text { Sentences }\end{array}$ & $\begin{array}{c}\text { Giving } \\
\text { Instruction } \\
\mathrm{s}\end{array}$ & $\begin{array}{l}\text { Checking } \\
\text { Understandin } \\
\text { g of } \\
\text { concepts, } \\
\text { talk, text or } \\
\text { instructions }\end{array}$ & $\begin{array}{c}\text { Eliciting } \\
\text { Languag } \\
\mathrm{e}\end{array}$ & $\begin{array}{l}\text { Focusin } \\
\mathrm{g} \\
\text { Learners } \\
, \\
\text { Attentio } \\
\mathrm{n}\end{array}$ & $\begin{array}{c}\text { Talking } \\
\text { about } \\
\text { Learnin } \\
\mathrm{g}\end{array}$ & $\begin{array}{c}\text { Giving } \\
\text { Feedbac } \\
\text { k }\end{array}$ & $\begin{array}{c}\text { Disciplinin } \\
\text { g and } \\
\text { Class } \\
\text { Control }\end{array}$ & $\begin{array}{c}\text { Informa } \\
\text { 1 or } \\
\text { Friendl } \\
\text { y Talk } \\
\text { with } \\
\text { Learner } \\
\text { s }\end{array}$ \\
\hline \multicolumn{11}{|c|}{ Total Numbers } \\
\hline NNS & 22 & 19 & 6 & 18 & 25 & 24 & 4 & 13 & 9 & 17 \\
\hline NS & 9 & 31 & 1 & 10 & 15 & 1 & 3 & 8 & 4 & 5 \\
\hline
\end{tabular}

As displayed in the table above, the results of the classroom observations indicated that the NNS instructors used Turkish mostly to elicit language $(\mathrm{N}=25)$, focus learners' attention $(\mathrm{N}=24)$ and explain grammar $(\mathrm{N}=22)$. $\mathrm{NS}$, on the other hand, used Turkish most frequently to translate vocabulary or sentences $(\mathrm{N}=31)$, elicit language $(\mathrm{N}=15)$ and check understanding of concepts, talk, text or instructions $(\mathrm{N}=10)$. Although NNS instructors widely used L1 to focus learners' attention in class, it was only observed once in the NS instructors' lessons. When the overall frequency ratio is considered, the NNS used Turkish 157 times while the NS used it 87 times.

\subsection{The Findings of the Think Aloud Protocols with NS and NNS Instructors}

In line with the results gathered from the questionnaire, the think-aloud protocols also revealed similar findings about the purpose of using L1 by two groups of instructors in EFL classrooms.

Firstly, when the NNS were asked why they used L1, they stated that they preferred to use it for error correction, attention gathering and explanation of new words and collocations. The following two excerpts clarify these points:

[...] In my courses, I mostly used Turkish for error correction and drawing attention to make sure that my students understand new words (NNS instructor, Think aloud protocol data, 23 ${ }^{\text {rd }}$ March, 2016).

[...] I think I used Turkish the most when I wanted to emphasize, explain or draw attention to a point and then make sure that my students understood new words and collocations (NNS instructor, Think aloud protocol data, 23 ${ }^{\text {rd }}$ March, 2016).

In addition, the same group of instructors stated that they used Turkish in their classrooms for informal talk to establish rapport with their students as well as to clarify complex grammatical structures as shown in the comment below:

[...] I use L1 for informal talk which aimed to build rapport with my students (NNS instructor, Think aloud protocol data, 23 ${ }^{\text {rd }}$ March, 2016).

[...] It seems that I use L1 more for explaining difficult grammar rules (NNS instructor, Think aloud protocol data, $23^{\text {rd }}$ March, 2016). 
Similarly, the NS said that they used Turkish to explain grammar rules, check vocabulary/grammar and student comprehension of the subject covered in the class. The following two quotations support this issue:

[...] I use Turkish to explain how grammar works or to check vocabulary and grammar (NS instructor, Think aloud protocol data, 23 ${ }^{\text {rd }}$ March, 2016).

[...] I use Turkish to check understanding because I want to make sure that the students understand what I taught in the course (NS instructor, Think aloud protocol data, 23 ${ }^{\text {rd }}$ March, 2016).

Besides, one of the NS used Turkish for humor saying that he believed that making jokes in L1 attracts students' attention and it also helps with the pacing of the lesson as displayed in quotation below:

[...] I used Turkish for humor, to make some jokes in class and sometimes just to get my students' attention. It also helps me with the pacing as we have to cover many subjects within a certain time limit (NS instructor, Think aloud protocol data, $23^{\text {rd }}$ March, 2016).

Finally, another NS said that he switched to Turkish to elicit language. If a word has an equivalent in Turkish, he would use it to focus attention and clarify the subject matter.

[...] I guess I use Turkish mostly for eliciting language. If I know that a word has a direct correlation with a Turkish word, then I use that Turkish word which helps me to focus my students' attention and clarify what I teach in my course (NS instructor, Think aloud protocol data, $23^{\text {rd }}$ March, 2016).

Furthermore, parallel to the perceptions and purposes of using Turkish in EFL classrooms, the reflections of the native and non-native instructors revealed that they mostly used Turkish to draw students' attention, clarify points that students have difficulty in understanding and establish rapport with the students. The four extracts below are the statements of the participants underlining these points:

[...] In this lesson I used Turkish to explain the new grammatical topic, past tense followed by the new complex words such as nomination and limitation (NNS instructor, Think aloud protocol data, 23 ${ }^{\text {rd }}$ March, 2016).

[...] I used Turkish in this lesson as I felt my students weren't paying attention, as they were really confused about the new grammar topic (e.g. past perfect) (NNS instructor, Think aloud protocol data, $23^{\text {rd }}$ March, 2016).

[...] In this lesson, I used Turkish when I faced with unanticipated problems with student comprehension. No matter how simply I explained some points, there were some students who were confused about the new topic which made me explain it in Turkish (NS instructor, Think aloud protocol data, 23 ${ }^{\text {rd }}$ March, 2016).

[...] In this lesson, I used Turkish to explain the complicated words. At the same time, I used Turkish to build rapport with my students and attract their attention. I think it works well (NS instructor, Think aloud protocol data, 23 ${ }^{\text {rd }}$ March, 2016).

Based on the reflections above, it is obvious that both groups of instructors had positive attitudes towards the use of L1 as a teaching strategy when used judiciously. Moreover, both groups of instructors agreed that the use of L1 can be a lifesaving teaching strategy particularly to attract the attention of the students, establish rapport and clarify certain points that students find difficult.

\section{Discussion}

The main purpose of this study was to figure out the perceptions, teaching practices and reflections of NS and NNS English instructors towards the use of learners' L1 (Turkish) as a teaching strategy in the EFL classroom. By comparing the findings, the researcher also aimed to see whether there was a significant difference between the teaching practices and reflections of these two groups of instructors. For these purposes, data were collected both quantitatively and qualitatively; and a mixed method research design was adopted for analysis. This chapter first discusses the results of this study referring to each research question and then provides with theoretical and pedagogical implications for further research and practice. 
The first research question intended to investigate the perceptions of both NS and NNS instructors in terms of effective usage of L1 in EFL classes and its advantages for both learners and instructors through an online questionnaire.

Considering the responses the participants gave for the first 12 items in the questionnaire, it is clear that both NS and NNS instructors believe that L1 is an essential strategy in the EFL classroom. Both groups agreed that L1 provides learners with opportunities to learn English more effectively and it also eases the instructors' teaching in a better way. These groups also agreed on the use of L1 to teach or explain complex vocabulary and complex grammar items. In a study by Tang (2002), the teachers participating in the study also indicated that they think the use of L1 was necessary to translate some difficult words and explain complex grammar points as well.

There are also other points where both groups of instructors strongly agreed that L1 should not be prioritized. These purposes are checking understanding, eliciting language and giving instructions. By looking at the findings, it can be concluded that NS and NNS instructors are in favor of using L1 for the purposes of translating or explaining difficult items, which are directly related to teaching. However, they would rather not use L1 for subsidiary purposes to teaching like giving instructions.

Apart from these items, NS and NNS instructors are of different opinions in terms of using L1 to give feedback and give suggestions on how to learn effectively. While a great many of NNS instructors think that using L1 is necessary to give learners feedback and teaching/suggesting learners how to learn English more effectively, not many NS instructors believe that it should be used for such purposes. This might be one reason why learners usually prefer to get feedback on their studies from their NNS instructors and why they see their NNS instructors as advisors to be consulted when they have a problem with their learning.

By looking at the perceptions of instructors about the advantages of using L1 to teach the TL, it is concluded that both NS and NNS instructors have a strong belief that L1 helps learners comprehend ambiguous or difficult concepts and grammar or vocabulary items, which saves them from a feeling of frustration when they have difficulty in understanding. They also believe that L1 makes learners more positive and less apprehensive in the classroom environment and this might be the reason why instructors indicated in the think aloud protocols that they like to use L1 for informal talk and jokes or building rapport with the learners. Similarly, Bruen and Kelly's (2014) study with twelve lecturers also suggest that the use of L1 in L2 classroom in justified situations can help reduce cognitive overload and learner anxiety. Therefore, it is possible to conclude that L1 can be used to lower the affective filter and help learners receive language input more easily.

From the point of teaching, both groups of instructors are L1-friendly for practical purposes. The questionnaire results show that many of them see L1 as a more effective way of disciplining or controlling the class. The results also show that another practical purpose of L1 use for most instructors is it is economical in terms of time. Having a busy schedule is a very common problem of almost all language instructors, especially when the instructors are responsible for teaching more than one grammar topic weekly. This may be a really tempting situation which can lead the instructors to use L1 to save time and continue in the course at a faster phase.

In brief, as shown in the questionnaire results that neither NS nor NNS instructors disclaim the benefits L1 brings to the EFL classroom. They seem to agree in many points such as using L1 for teaching complex grammar and abstract vocabulary, difficult concepts and expressions. The rationale behind the belief that L1 is necessary for such usages is that, L1 eliminates the confusion in learners' minds and thus makes learners less stressful and more open to language learning. Moreover, both groups of instructors think that using L1 is a very effective way of asserting authority in the classroom and save time when needed. From these perceptions, we can finally conclude that instructors do not support the use of L1 only for the good of the learners but also to their own advantages.

Furthermore, the second and third research questions aimed to discover both the frequency ratio of L1 use and the purposes for L1 use by NS and NNS as well as the differences between the use of L1 by these two groups. The findings were based on eight classroom observations conducted with NS $(\mathrm{N}=4)$ and NNS $(\mathrm{N}=4)$ instructors in elementary level classrooms.

The basic assumption of the researcher before this study was that NNS instructors usually have a greater tendency to use L1 in their classes than NS do. The questionnaire stage of the study partially proved this assumption since more than half of the NNS instructors chose higher percentages of L1 use at a time. The results of the observation were even more remarkable as NNS instructors depended on L1 almost two times more than NS instructors did. Based on the findings above, it is no wonder that the common prejudgment that NNS instructors depend more on their mother tongue is actually true. One reason for this could be that this was the way they were taught the target language. Since most of the NNS instructors also learned English from NNS instructors, some of them were also exposed to certain amount of instruction in their mother tongue, which may have affected their beliefs and perceptions about language teaching.

Another possibility might be that they feel more confident when they use L1 and believe that learners will be able to learn the target language better when explained in their mother tongue. Some of the NS instructors have a very interesting statement about this issue; they stated that if they were more fluent in Turkish or if they were more confident about their Turkish use, they would definitely seek ways of using it more in class. In a study by Arva and Medgyes, one of the instructors makes a remarkable expression about the importance of L1; "I can't explain fully, especially with beginners, and it can be frustrating." while another one admits "It must be wonderful to speak Hungarian and, if students have a problem, to explain it in Hungarian" (2000, p. 362). Considering these statements, it can be assumed that, speaking learners' L1 more fluently and confidently is a tempting factor for instructors to use it as a teaching 
strategy since the knowledge of L1 means having a common ground for more effective communication and comprehension.

As for the purposes of L1 use for instruction, the researcher assumed in the pre-research stage that NNS instructors would depend on it most to 'explain grammar' and 'translate vocabulary or sentences'. The observations showed that while these two strategies were still among the top practices of the NNS instructors, 'translating vocabulary or sentences' was surprisingly the most commonly used strategy by NS instructors. Another assumption that the researcher had before the research was NS would use learners' L1 mostly for informal and friendly talk with the learners or telling jokes to them in order build rapport and break the cultural barriers between them. In Ford's (2009) study, majority of the instructors stated that they consciously used English in class in order to create a positive and friendly classroom atmosphere, which will also improve learning opportunities. Although this was also something frequently remarked by the NS instructors in the think aloud protocols, they barely used L1 for this purpose in their classrooms. As a matter of fact, NNS instructors used L1 for this purpose considerably more than NS. This might indicate that allowing time for informal talk to build rapport with the learners is as a significant issue for the NNS as it is for NS instructors. It can also be concluded that NS instructors place higher value on L1 for explaining complex grammar and vocabulary items to ease comprehension than using it for informal talk.

When questionnaire results are compared to classroom observations, it is seen that there are strategies NS and NNS instructors use more frequently in practice than they think they do; 'checking understanding' and 'eliciting language'. In fact, using L1 to elicit language was the most popular teaching strategy used by both groups. By considering the practices of instructors, it can be possible to suggest that this is something strongly related to checking comprehension. It was observed that the instructors started off their lessons using English and they conducted presentation and eliciting stages in English. However, when the learners remained unresponsive during these stages, the instructors had the impression that what they had been saying so far was not delivered to learners. Therefore, the instructors immediately switched to the mother tongue in order to prevent any misunderstanding or incomprehension. Schweer's (1999, p. 9) study also provides significant evidence about the use of L1 for the same purpose. One of the teachers in his study points out "It is important as you go along to periodically make sure students are understanding. I will ask, "Does everyone understand?", "Who can say what I just said in Spanish?" and I wait until I get an acceptable translation.". These findings may suggest that L1 has a confirmatory role which is widely approved by both NS and NNS instructors.

The greatest discrepancy observed between NS and NNS instructors in the lessons was 'focusing learners' attention'. Although NS instructors highlighted its significance both in the questionnaire and think aloud protocols, they did not use it in the classroom. This might be either because the lesson was really interesting and engaging for the learners or because it was too simple for them. This, however, does not mean that the NS instructors did not focus learners' attention at any point during the observed lessons. Rather, they did this by using other techniques such as raising or lowering their voices or using their mimes and gestures, which suggests that although NS highly promote the use of L1 to focus attention, they would rather resort to other techniques than L1 to do this.

The last research question of the study investigated the reflections of NS and NNS instructors and sought what kinds of differences the two groups of instructors had about using L1 for instructive purposes. The data were obtained through think aloud protocols from the instructors whose lessons were observed. The findings of the think aloud protocols revealed that both NS and NNS instructors' reflections on L1 use are based on the same beliefs and opinions; and their justifications for L1 use comply perfectly with these opinions.

One of the most frequently emphasized points of the think aloud protocols was L1's efficiency to clear up confusion, especially when correcting errors, explaining grammar and teaching vocabulary. The instructors from both groups indicated that while explaining grammar and vocabulary, L1 is particularly important as it eases the comprehension of abstract and difficult concepts, which saves learners from a feeling of frustration they have when they do not understand. It can be inferred from these statements that rather than rendering the learners confused and watch them try to deal with the language itself, the instructors would rather explain everything to learners simply in a language they can understand and then let them deal with the practice and production stages. In a similar manner, Storch and Wigglesworth (2003, p. 760) suggest that " the use of L1 allows learners to analyze language and work at a higher level than would be possible were they restricted to sole use of their L2."

The instructors also implied that at some points, the use of L1 can even help better retention and memory if there are strong associations made between the two languages while teaching. Yet, the instructors claim these points to be valid only if they are teaching lower levels, as the upper levels would have enough language background to be able to deal with these difficulties. In a similar fashion, Cook (2001) argues that L1 should be used for lower-proficiency students as they have very little target language linguistic knowledge. Thus, it can be inferred that L1 undertakes an associative role between the two languages, which provides learners with an efficient way of comprehending the target language.

Another point frequently underlined by the instructors was L1's efficiency in timesaving. The instructors pointed out that they generally try to save time while teaching grammar and correcting errors. Instructors from both groups indicated that they first do their best to introduce any target language in English in the simplest way possible; preparing well-planned lessons supported with lots of visuals and extra materials that can help learners to gain awareness by using their background knowledge. However, they also pointed out that in some cases the learners may not be able to get the message in spite of all the materials and the effort the instructors have put through. Even when this is the case, they said that they would still not resort to L1 immediately and they would still try to explain the point from the start once or twice. They stated that they switched to L1 only if all the previously mentioned stages seem to fail for at least some 
students because they would no longer want to waste their time in class sticking to one single point, as their daily or weekly program is too busy to handle this. The NS instructors who do not have enough proficiency in Turkish, on the other hand, indicated that they even asked their NNS partners to go through the introduced language item or they simply directed the learners with difficulties to their non-native instructors for a short tutorial. The instructors made similar statements for correcting errors and pointed out that in cases when the learners have difficulty in noticing or correcting their errors, they try to help them notice by using English first. However, if the learners cannot or if they start to produce further errors, they have to intervene in the error correction process with learners' L1 in order to prevent a bigger problem and gain them awareness.

Finally, the most frequently highlighted and supported function of L1 use in class for most instructors was 'focusing attention'. The instructors stated that they used this function a lot as it provides them with many benefits such as changing the pace of the lesson, eliminating distraction of learners, raising awareness on what is being taught, and controlling and disciplining the class without threatening or reprimanding learners. They indicated they used this strategy particularly for the purposes of controlling the class and eliminating learner distraction. As a matter of fact, the instructors believe that this strategy can also be implemented successfully by using English as well; however they still do not believe that it is a good idea and they would still prefer to use Turkish. Their claim is that during the lesson, every word uttered in English sounds like white noise after a while and at this point, any instruction, warning or reprimand directed at the learners is seemingly futile. In such situation, hearing Turkish brings them out of a trance after hearing English for a long time; and English never makes such a strong effect as Turkish does to suddenly alert learners. Actually, they pointed out that they would prefer to use any language other than English to eliminate distraction.

\section{Pedagogical Implications}

This study has notable implications to be taken for granted about the use of L1 in EFL classrooms. As previously discussed, several researchers have highlighted various practical uses and advantages of using the learners' mother tongue in EFL classroom both for learners and for instructors. Most of the previous studies in the literature, however, focus either on how the non-native instructors of English use learners' L1 to their learners' or their own advantage or how learners used their L1 to learn the target language in the monolingual setting. To fill in this gap, the present study was designed to go beyond what is already known and tried to gain a new perspective about other users of learners' L1 in this setting; native speakers of English. Therefore, in this study, learners were not involved in data collection process, yet non-native instructors of English took part in it in an attempt to investigate the key roles of both groups of instructors in EFL classroom setting. The data collected depended mainly on instructors' perceptions and reflections as well as their teaching practices in order to see whether these perceptions and reflections are implemented into their actual teaching practices.

Furthermore, this study has significant implications both for NS and NNS EFL instructors and administrators of language programs and institutions as well. First of all, the study presents that not only NNS instructors of English use their shared knowledge of L1 with the learners but also the NS who speak learners' L1 (regardless of their proficiency or fluency) admit that they make use of learners' L1 in various situations and for various purposes. Besides, they claim that there are many benefits of L1 as a teaching strategy when used judiciously. In this respect, foreign language instructors may want to go through their current language teaching approaches, especially if they have adopted a 'target-language-only' approach, and reconsider the cognitive or practical benefits regarding the use of L1 in the EFL classrooms. Likewise, these insights may also help language program administrators reconsider and change their attitudes towards hiring native instructors only. Since this study signifies that many native instructors believe in the efficiency and practicality of using learners' L1 in certain circumstances, they tend to use L1 in the classroom as their non-native colleagues do. As this is the case, it might not be wrong to assume that hiring only native instructors will not necessarily mean the total removal of L1 from the classroom provided that it is monolingual.

Regarding the aforementioned points, the findings of this study are significant for the efficiency and preferability of L1 use in EFL classrooms. Thus, it may serve as a model study for other studies which will aim to support the use of mother tongue in second/foreign language classrooms.

\section{Limitations}

The present study has some limitations to be taken into consideration. One of the main limitations in this study is the limited number of participants. As the study was conducted only with elementary class instructors who were limited in number, the internal validity could have been affected. Besides, the study is based on the data gained from both NS and NNS instructors who worked in the same preparatory program, which again means that the sample data could only be generalized to this population. This limits the external validity of the results, as they cannot be generalized to different contexts. Second, the proficiency level of the NS instructors regarding Turkish language was not assessed or tested. Although a correlation was made between the NS instructors' Turkish proficiency/fluency level and the impact of their Turkish level on their teaching practice, their L1 proficiency was only gathered from the questionnaire results which might have influenced the obtained results. The final limitation of this study is the lack of external researcher. Since the researcher herself works in the same institution, the objectivity of the study might be influenced. This can be considered as another threat to external validity. 


\section{Recommendations for Further Research}

This study has a few important recommendations for further research. First of all, a further study could be conducted to examine native and non-native instructors' perceptions on some other uses of L1 as a teaching strategy such as teaching discourse, managing tasks or discussing cross-cultural issues in the EFL classroom. Second, as this study was conducted with instructors teaching elementary level classes, their perceptions and reflections were mainly related to this particular group of students. Linked as a further step of this study, another study could be conducted to explore the different purposes for which L1 can be used in different proficiency level classrooms. Third, as previously stated, none of the native participants' proficiency in learners' L1 in this study was above 'intermediate'. As some native instructors indicated in the think aloud protocols that they would use L1 more were they more proficient in it, a further study can be conducted with native instructors who are more proficient or fluent in learners' L1.Another comparative study can be conducted about native and non-native EFL instructors' perceptions about the advantages and/or disadvantages of L1 use in class with an attempt to find out whether advantages outweigh the disadvantages or vice versa. Finally, a follow up study could be carried out with the language learners to find out and compare their perceptions about the advantages and/or disadvantages of L1 use in class.

\section{Conclusion}

The results of this research study revealed that the use of L1 as a teaching strategy has positive implications in the EFL classroom. The data collected through the questionnaires, observations and think aloud protocols indicated that, the judicious use of L1 to teach the target language is welcomed and favored both by native and non-native instructors for various purposes such as clarifying TL meaning, checking comprehension, focusing learner attention and building rapport with learners. The findings of the study also proved that the perceptions, teaching practices and reflections of both native and non-native instructors about the use of L1 bear strong similarities with each other.

To conclude, the aim of the study was to explore the perceptions of native and non-native instructors about the effectiveness of L1 to teach TL at a private (non-profit, foundation) university language preparatory program in Turkish EFL context. For this reason, the study focused on the most commonly used strategies of L1 to teach the TL and aimed to find out what native and non-native instructors of English did differently from each other in practice and why. With the obtained findings, this study suggests that the long-forgotten L1 should be re-evaluated as a teaching strategy in the EFL classroom for its various benefits for both learners and instructors. 


\section{References}

Al-Buraiki, M.A. (2008). The L1 in young learner classrooms: Teachers' views and practices. Retrieved November 2015 from www.moe.gov.om/Portal/sitebuilder/sites/EPS/English/MOE/.../Ch2.pdf

Al-Hinai, M. K. (2006). The use of the L1 in the elementary English language teaching in Oman. Classroom Research in English Language Teaching in Oman. Sultanate of Oman: Ministry of Education, 8-14.

Arnett, K. (2001). The accommodation of grade 9 students with learning disabilities in the applied core French program. Unpublished master's thesis, The Ontario Institute for Studies in Education of the University of Toronto, Canada.

Árva, V., \& Medgyes, P. (2000). Native and non-native teachers in the classroom. System: 28(3), 355-372.

Atkinson, D. (1987). The mother tongue in the classroom: A neglected resource?. ELT journal, 41(4), 241-247.

Atkinson, D. (1993). Teaching monolingual classes. London: Longman.

Auerbach, E. R. (1993). Reexamining English only in the ESL classroom. Tesol Quarterly: 9-32.

Bergman, M. M. (2011). The good, the bad, and the ugly in mixed methods research and design. Journal of Mixed Methods Research: 5(4), 271-275.

Berry, D., \& Dienes, Z. P. (1993). Implicit learning: Theoretical and empirical issues. Psychology Press.

Brooks, F. B., \& Donato, R. (1994). Vygotskyan approaches to understanding foreign language learner discourse during communicative tasks. Hispania, 262-274.

Brown, H. D. (2000). Principles of language teaching and learning. White Plains, NY: Longman.

Bruen, J., \& Kelly, N. (2014). Using a shared L1 to reduce cognitive overload and anxiety levels in the L2 classroom. The Language Learning Journal, 1-14.

Burden, P. (2000). The use of the students' mother tongue in monolingual English" conversation" classes at Japanese universities. Language Teacher Kyoto JALT, 24(6), 5-10.

Butzkamm, W. (2003). We only learn language once. The role of the mother tongue in FL classrooms: death of a dogma. Language Learning Journal, 28(1), 29-39.

Calderaro, L. D. C. (1998). Considerations on Teaching Translation. Translation Journal, 2(3).

Canagarajah, A. S. (1999). Resisting linguistic imperialism in English teaching. Oxford: Oxford University Press.

Carrell, P. L., \& Eisterhold, J. C. (1983). Schema theory and ESL reading pedagogy. TESOL quarterly, 553-573.

Carroll, J. (1968). Basic and applied research in education: Definitions, distinctions, and implications. Harvard Educational Review, 38(2), 263-276.

Charters, E. (2003). The use of think-aloud methods in qualitative research an introduction to think-aloud methods. Brock Education Journal, 12(2).

Chaudron, C. (1988). Second language classrooms: Research on teaching and learning. Cambridge: Cambridge University Press.

Claridge, M. T., \& Lewis, T. (2005). Coaching for effective learning: A practical guide for teachers in health and social care. London: Radcliffe Publishing.

Cole, S. (1998). The use of L1 in communicative English classrooms. Language Teacher Kyoto JALT, 22, 11-14.

Connick-Hirtz, S. (2001). Using the first language in second language instruction. In TESL-EJ Forum. http://www.aitech.ac/iteslj./html.

Cook, V. J., Long, J., \& McDonough, S. (1979). First and second language learning. The mother tongue and other languages in education, CILTR, 7-22.

Cook, V. (1999). Going beyond the native speaker in language teaching. TESOL quarterly, 185-209.

Cook, V. (2001). Using the first language in the classroom. Canadian Modern Language Review, 57(3), 402-423.

Cook, V. (2002). Background to the L2 user. Portraits of the L2 user, 1, 1-28.

Cook, G. (2007, April). Unmarked Improvement: values, facts, and first languages. In IATEFL Conference, Aberdeen (pp. 18-20).

Crystal, D. (2000). Emerging Englishes. English Teaching Professional, 14, 3-6.

Davies, A. (2000). Native speaker. Blackwell Publishing Ltd.

DeKeyser, R. M. (2000). The robustness of critical period effects in second language acquisition. Studies in second language acquisition, 22(04), 499-533.

DeKeyser, R. M. (81). Larson-Hall., J.(2005). What does the critical period really mean. Handbook of bilingualism: Psycholinguistic approaches, 88-108.

Denzin, N. (1970). Strategies of multiple triangulation. The research act in sociology: A theoretical introduction to sociological method, 297, 313. Chicago. 
Devrim, D. Y., \& Bayyurt, Y. (2010). Students ${ }^{e}$ Understandings and Preferences of the Role and Place of „Culture ${ }^{e c}$ in English Language Teaching: A Focus in an EFL context. TESOL Journal, 2(1), 4-23.

Dujmović, M. (2007). The use of Croatian in the EFL classroom. Metodički obzori, 2(3), 91-101.

Eldridge, J. (1996). Code-switching in a Turkish secondary school. ELT journal, 50(4), 303-311.

Ellis, N. C. (2005). At the interface: Dynamic interactions of explicit and implicit language knowledge. Studies in second language acquisition, 27(02), 305-352.

Ellis, R. (1984). Classroom Second Language Development: A Study of Classroom Interaction and Language Acquistion. Pergamon.

Ellis, R. (1988). Classroom second language development. New York: Prentice Hall.

Ellis R. (1994). The study of second language acquisition. Oxford: Oxford University Press.

Ellis, R. (1997). SLA Research and Language Teaching. Oxford University Press, 198 Madison Avenue, New York, NY 10016-4314.

Ellis, R. (2005). Measuring implicit and explicit knowledge of a second language: A psychometric study. Studies in second language acquisition, 27(02), 141-172.

Ford, K. (2009). Principles and practices of L1/L2 use in the Japanese university EFL classroom. JALT journal, 31(1), 63-80.

Greene, J. C., Caracelli, V. J., \& Graham, W. F. (1989). Toward a conceptual framework for mixed-method evaluation designs. Educational evaluation and policy analysis, 11(3), 255-274.

Grant, N. (1993). Preface to Atkinson, David. Teaching Monolingual Classes.

Hall, R. (2012). Mixed methods: In search of a paradigm. Vortrag. Download (am 10.01. 2013) unter: http://www. auamii. com/proceedings_Phuket_2012/Hall.pdf.

Harbord, J. (1992). The use of the mother tongue in the classroom. ELT journal, 46(4), 350-355.

Harley, B., \& Hart, D. (1997). Language aptitude and second language proficiency in classroom learners of different starting ages. Studies in second language acquisition, 19(03), 379-400.

Harmer, J. (2007). The practice of English language teaching.

Holthouse, J. (2006, March). The Role of the Mother Tongue in EFL Classrooms. In Gaikokugokyoiku Forum, 5, 27$37)$.

Inbar-Lourie, O. (2010). English only? The linguistic choices of teachers of young EFL learners. International Journal of Bilingualism, 14(3), 351-367.

Johnson, R. B., Onwuegbuzie, A. J., \& Turner, L. A. (2007). Toward a definition of mixed methods research. Journal of mixed methods research, $1(2), 112-133$.

Kavaliauskienè, G. (2009). Role of mother tongue in learning English for specific purposes. ESP World, 8(1), 2-8.

Kayaoğlu, M. N. (2012). The use of mother tongue in foreign language teaching from teacherse practice and perspective. Pamukkale Üniversitesi Eğitim Fakültesi Dergisi, 32, 25-35.

Krashen, S. (1982). Principles and practice in second language acquisition (pp. 1982-1982). Pergamon: Oxford.

Kuhn, T. (1970). S. 1962. The structure of scientific revolutions.

Lado, R., Baldwin, B., \& Lobo, F. (1967). Massive Vocabulary Expansion in a Foreign Language Beyond the Basic Course: The Effects of Stimuli. Timing and Order of Presentation (Washington, DC: HEW, 1967).

Lameta-Tufuga, E. (1994). Using the Samoan language for academic learning tasks. Unpublished MA thesis, Victoria University of Wellington, New Zealand.

Larsen-Freeman, D. (2008). Techniques and principles in teaching $2^{\text {nd }}$ edition. NY: OUP.

Latham, B. (2007). Sampling: What is it. Quantitative Research Methods-Texas Tech University.

Laufer, B., \& Shmueli, K. (1997). Memorizing new words: Does teaching have anything to do with it?. RELC journal, 28(1), 89-108.

Lenneberg, E. H., Chomsky, N., \& Marx, O. (1967). Biological foundations of language (Vol. 68). New York: Wiley.

Levine, G. S. (2003). Student and instructor beliefs and attitudes about target language use, first language use, and anxiety: Report of a questionnaire study. Modern Language Journal, 343-364.

Lightbown, P. M., \& Spada, N. (2013). How Languages are Learned 4th edition. Oxford University Press.

Littlewood, W., \& Yu, B. (2011). First language and target language in the foreign language classroom. Language Teaching, 44(01), 64-77.

Liu, J. (2008). L1 use in L2 vocabulary learning: Facilitator or barrier. International Education Studies, 1(2), p65.

Lohr, S. (2009). Sampling: design and analysis. Nelson Education.

Macaro, E. (1997). Target language, collaborative learning and autonomy (Vol. 5). Multilingual matters. 
Macaro, E. (2005) Codeswitching in the L2 classroom: A Communication and learning strategy. In E. Llurda (ed.) NonNative Language Teachers: Perceptions, Challenges and Contributions to the Profession (pp. 63-84). New York: Springer.

Macaro, E. (2009). Teacher use of codeswitching in the second language classroom: Exploring 'optimal'use. First language use in second and foreign language learning, 35-49.

Macdonald, C. (1993). Using the target language. Mary Glasgow.

Mahmutoğlu, H., \& KICIR, Z. (2013). The Use of Mother Tongue in EFL Classrooms. LAÜ Sosyal Bilimler Dergisi, 4(1), 49.

Masrai, A., \& Milton, J. (2015). An Investigation of the Relationship between L1 Lexical Translation Equivalence and L2 Vocabulary Acquisition. International Journal of English Linguistics, 5(2), 1.

Mattioli, G. (2004, October). On native language intrusions and making do with words: Linguistically homogeneous classrooms and native language use. In English teaching forum, 42 (4), 20-25.

Mayberry, R. I., \& Lock, E. (2003). Age constraints on first versus second language acquisition: Evidence for linguistic plasticity and epigenesis. Brain and language, 87(3), 369-384.

Mayo, M. D. P. G., \& Lecumberri, M. L. G. (Eds.). (2003). Age and the acquisition of English as a foreign language (Vol. 4). Multilingual Matters.

Meyer, H. (2008). The pedagogical implications of L1 use in the L2 classroom. Maebashi Kyoai Gakuen College Ronsyu, 8, 147-159.

Miles, M. B., \& Huberman, A. M. (1994). Qualitative data analysis: An expanded sourcebook. Sage.

Miles, R. (2004). Evaluating the use of L1 in the English language classroom (Doctoral dissertation, University of Birmingham).

Mishima, T. (1967). An experiment comparing five modalities of conveying meaning for the teaching of foreign language vocabulary. University Microfilms, Incorporated.

Morrow, S. L. (2005). Quality and trustworthiness in qualitative research in counseling psychology. Journal of counseling psychology, 52(2), 250.

Nation, P. (2003). The role of the first language in foreign language learning. Asian EFL Journal, 5(2), 1-8.

Nazary, M. (2008). The role of L1 in L2 acquisition: Attitudes of Iranian university students. Novitas-Royal, 2(2), 138153.

Nunan, D. (1999). Second Language Teaching \& Learning. Heinle \& Heinle Publishers, 7625 Empire Dr., Florence, KY 41042-2978. Nation, P. (2003). The role of the first language in foreign language learning. Asian EFL Journal, 5(2), $1-8$.

Prodromou, L. (2002). From mother tongue to other tongue: what is the place of the learners' mother tongue in the EFL classroom.

Rolin-Ianziti, J., \& Varshney, R. (2008). Students' views regarding the use of the first language: An exploratory study in a tertiary context maximizing target language use. Canadian modern language review, 65(2), 249-273.

Ross, N. J. (2000). Interference and intervention: Using translation in the EFL classroom. Modern English Teacher, $9(9), 61-66$.

Schweers Jr, W. (1999, April). Using L1 in the L2 classroom. In English Teaching Forum (Vol. 37, No. 2, pp. 6-9).

Sharma, K. (2006). Mother tongue use in English classroom. Journal of NELTA, 11(1-2), 80-87.

Shih, F. J. (1998). Triangulation in nursing research: issues of conceptual clarity and purpose. Journal of advanced nursing, 28(3), 631-641.

Sinclair, J. M., \& Coulthard, M. (1975). Towards an analysis of discourse: The English used by teachers and pupils. Oxford Univ Pr.

Singleton, David, and Lengyel, Zsolt. (1995). The Age Factor in Second Language Acquisition. Clevedon: Multilingual Matters.

Skinner, D. C. (1985). Access to meaning: The anatomy of the language/learning connection. Journal of Multilingual \& Multicultural Development, 6(5), 369-388.

Smith, M. S. (1981). Consciousness-Raising and the Second Language Learner1. Applied linguistics, 2(2), $159-168$.

Storch, N., \& Wigglesworth, G. (2003). Is there a role for the use of the L1 in an L2 setting?. TESOL quarterly, 37(4), 760-769.

Swan, M. (1985). A critical look at the communicative approach (1). ELT journal, 39(1), 2-12.

Tang, J. (2002, January). Using L1 in the English classroom. In English Teaching Forum (Vol. 40, No. 1, pp. 36-43).

Teddlie, C., \& Tashakkori, A. (2003). Major issues and controveries in the use of mixed methods in the social and behvioral sciences. Handbook of mixed methods in social \& behavioral research, 3-50. 
Varonis, E. M., \& Gass, S. (1985). Non-native/non-native conversations: A model for negotiation of meaning. Applied linguistics, 6(1), 71-90.

Viney, P. (2005). Using students' native language in class. Retrieved 10 November 2005 from www.eltnews.com/features/teachingideas/008_pv.shtml

Wharton, C. (2007). Informed use of the mother tongue in the English language classroom. Retrieved April, $2,2014$.

Willis, Jane. 1991. Teaching English through English. Longman. ISBN 0-582-74608-6.

Willis, Jane. 1996. A Framework for Task-Based Learning. New York: Longman. ISBN 9780582259737.

Winke, P. M. (2007). The psychology of the language learner: Individual differences in second language acquisition. Studies in Second Language Acquisition, 29(1), 143-144.

Yavuz, F. (2012). The attitudes of English teachers about the use of L1 in the teaching of L2. Procedia-Social and Behavioral Sciences, 46, 4339-4344. 